\title{
Ueber den Bau der Magenschleimhaut ${ }^{1}$ ). Von
}

Nikolai Trinkler.

(Gekrönte Preisschrift der Universität Charkow).

Hierzu Tafel X und XI.

Bei meinen Untersuchungen musste ich, da ich mich nicht bloss anf die Erforschung des Baues der Magenschleimhaut höherer Thiere (Hund, Katze, Kaninchen, Ratte, Maus, Igel) beschränkte, sondern auch soviel als möglich zur Vergleichung das Studium niederer Wirbelthiere (Emys europaea, Tropidonotus natrix, Rana temporaria, Triton, Cyprinus carpio, Cobitis fossilis, Esox lucius, Perca fluviatilis) heranzog, die gewöhnlichen Bearbeitungs- und Färbungsmethoden vielfach abändern.

Der Magen wurde bei dem eben durch Stich oder Oeffnung der Carotis getödteten Thiere rasch ausgeschnitten, wobei ein Stück vom Oesophagus und vom Duodenum mitgenommen wurde und alsdann längs der grossen Curvatur geöffnet. Darauf wurde die Oberfläche der Schleimhaut, noch ehe sie vom Schleim und den Resten der Contenta gereinigt worden war, an verschiedenen Stellen mit Lakmuspapier gepriff, alsdann erst nach Verlauf einiger Zeit vermittelst eines Stromes destillirten Wassers abgewaschen.

Die Schleimhaut wurde nun bei Thieren mit dickwandigem Magen von der äusseren Muskelschicht abpräparirt und in möglichst gleiche Sticke zerschnitten, von denen einige in erhärtende Flüssigkeiten gebracht wurden, andere dagegen in indifferente (Humor aquaeus, Jodserum, CINa $0,4-0,6 \%$ ) zur Untersuchung im frischen Zustande.

1) Eine sehr ausführliche literarhistorische Einleitung, welche Verf. gegeben hatte, ist nicht zum Abdrucke gekommen. Sollten also hie und da Literatur-Nachweise vermisst werden, so fällt dies dem Verfasser nicht zur Last. Waldeyer. 
Um bei diesen letzteren Fäulniss (die Untersuchungen wurden während der heissen Jahreszeit angestellt) za vermeiden, wurden dieselben in einer Atmosphäre von Wasserdampf und Carbolsäure gehalten; endlich wurden häufig die Untersuchungen ohne jeglichen Zusatz irgend welcher Flüssigkeit vorgenommen.

Grösstentheils benutzte ich zur Erhärtung die Müller'sche Flissigkeit, welche, nach meiner Ansicht, bisweilen durch keine andere zu ersetzen ist; ausserdem brauchte ich Chromsäure $(0,5-$ $1 \%$ ), Picrinsäure und Alkohol von verschiedener Stärke; es ist dabei zu bemerken, dass die Präparate niemals unmittelbar in Alkohol gebracht wurden, sondern vorläufig auf ein bis zwei Tage in Müller'sche Flisssigkeit. Bei Erhärtung in Spiritus wurde zuerst schwacher genommen und erst später die Präparate allmählich in absoluten Alkohol iibertragen. An diese Regel muss man sich streng halten bei zarten Präparaten, wie z. B. die Schleimhaut der Fische, bei welchen, wenn man die Präparate sogleich in absol. Alkohol bringt, eine allzustarke Schrumpfung aller Elemente eintritt.

Die Osmiumsäure benutzte ich in schwachen Lösungen von $0,1-0,5 \%$. Nach Bearbeitung mit derselben wurden die Präparate lange Zeit mit Wasser ausgewaschen, dann in eine gesättigte Lösung von essigsaurem Kali gebracht, und alsdann in Glycerin untersucht.

Zur Maceration des Epithels und der Drüsenelemente wurde ebenfalls Müller'sche Fliissigkeit benutzt, allein oder im Gemisch mit Chlornatrium; alsdann Alkohol ( $1 / 3)$, Chloralhydrat ( $5 \%$, chromsaures Ammoniak, Kochsalzlösung $(35 \%)$ und eine Mischung von 1 vol. Chromsäure $1 / 50 \%, 1$ vol. Chloralhydrat $(5 \%)$ und einigen Tropfen Essigsäure. Diese Mischung, sowie Müll. Flüssigkeit mit schwacher Kochsalzlösung verdünnt (Prof. Kutschin's Methode) gaben mir ausgezeichnete Resultate.

Bei der Färbung nahm ich die von $\mathrm{Heidenhain}{ }^{1}$ ) emptohlene Methode in Betracht. Ich habe immer die langsame Färbung mit schwachen Lösungen der raschen Färbung vorgezogen, aber die erstere Art ist nicht immer anwendbar und nicht selten erhielt ich

1) Heidenhain, R.: „Untersuchungen über del Bau der Labdrüsen“ Arch. f. mikr. Anatomie Ba. VI. p. 402. 
ganz andere Resultate, als Heidenhain, selbst wenn ich auf's Genaueste alle Vorsichtsmaassregeln inne hielt.

Ausserdem benutzte ich bei meinen Untersuchungen Lakmus und Chlorophyll, wobei das erstere mir zugleich als mikroskopisches Reagens diente. Damit Lakmus aber sowohl als Färbungsmittel als auch als mikrochemisches Reagens zugleich benutzt werden könne, ist es nothwendig, dass der Aufguss von bedentender Concentration sei und nebenbei von unbedingt neutraler Reaction. Die zu schwachen Lösungen, die ich zu Anfang anwendete, gaben nicht die gewtinschten Resultate.

Chlorophyll als färbende Substanz erhielt ich auf folgende Weise: Die Blätter unserer gewöhnlichen Syringa vulgaris werden mit starkem Spiritus aufgesetzt und die ungefähr nach 24 Stunden erhaltene Fltissigkeit von dunkler Farbe wird filtrirt, das Filtrat dann auf dem Wasserbade eingedampft. Der geringe trockene Ruickstand wird in einer geringen Menge destillirten Wassers gelöst und von Neuem filtrirt. Dieses Filtrat hat eine schöne dunkelgrüne Farbe mit einem Stich in's Braune. Die weitere Behandlung der Präparate war die gewöhnliche. Da ich hauptsächlich die Untersuchungen von $\mathrm{Heidenhain}$ und Rollett im Auge hatte, bemühte ich mich natürlich beim Studium des Baues der Magenschleimhaut verschiedener Thiere, die Drïsen in den verschiedenen functionellen Zuständen zu erforschen, mit anderen Worten die Drüsen del Schleimhaut bei hungernden und gefutterten Thieren zu untersuchen. Ich war aber gezwungen, in Bezug auf gewisse Umstände bei Erklärung einiger Verhältnisse der Drusen und der sie zusammensetzenden Elemente, die Schleimhaut auch nach Einwirkung stärkerer Reize zu untersuchen, als die, welche man durch die Fütterung allein erhält.

Vom Standpunkte einiger Pathologen aus ${ }^{1}$ ) schien es mir vollkommen richtig; auch den Entzündungszustand und die mit demselben verbundenen Veränderungen in den mikroskopischen Bildern an verschiedenen Abtheilungen der Schleimhaut zu studiren. ' $\mathrm{u}$ diesem Maximum von Reizung, das bis an pathologische $\mathrm{Zu}$ stände reicht, gelangte ich dadurch, dass ich die Thiere mit gewissen Stoffen fuitterte, welche jedenfalls die Drüsenelemente der

1) Ebstein: Virch. Archiv. 1872. LV. p. 469. (Ref. nach. Uhle u. Wagner, Handbuch der allgemeinen Pathologie. Russisch. 1874. p. 421.) 
Magenschleimhaut stärker functioniren machen, als die gewöhnliche Speise. Za solchen Stoffen zählte ich Phosphor und Alcohol.

Das Epithelium, welches die Oberfläche der Magenschleimhaut bedeckt, ist bei allen Thieren fast ohne Ausnahme von cylindrischer oder conischer Form. Höhe und Grösse der Zellen schwanken innerhalb bestimmter Grenzen, nichts desto weniger erhält sich die Grundform iiberall.

Bei Säugethieren zeigt das Epithel im vollkommen frischen Zustande in humor aquaeus oder Jodserum folgende Verhältnisse: Der obere, breitere Theil der Zellen erscheint fast homogen, von matter Farbe, aufgequollen und bisweilen gänzlich zerfliessend, ohne scharfe Contouren. Dieser homogene Theil der Zellen ist nichts anderes als der Ausdruck der Schleimmetamorphose des Protoplasma im oberen Theil der Zellen. In der Richtung zum unteren Theil hin verschmälern sich die Zellen etwas und werden seitlich eingefasst von einer deutlich hervortretenden Membran, welche bei seitlicher Ansicht in Form eines doppelt contourirten Streifens erscheint, welcher an freien Theil der Zellen aufhört. Nicht selten jedoch werden in diesem homogenen Theile einzelne glänzende Körnchen von grösserem oder geringerem Umfange angetroffen. Die homogene Abtheilung der Zelle (Prof. Biedermann's) ist an ihrem untern Theil gewöhnlich scharf getrennt von der folgenden, etwas breiteren Abtheilung, welche einen Kern von etwas verlängerter Form einschliesst und ein stark körniges Protoplasma enthält. Diese Abtheilung der Zelle werde ich „Kö rper" nennen; dieselbe setzt sich ohne merkbare Veränderung in der Form in den schmäleren, etwas verlängerten Fuss fort, oder zeigt sich im Niveau des Kerns leicht erweitert und stärker körnig: (s. Taf. X, Fig. 2).

Bei Einwirkung von Essigsäure erfolgt in dem schleimigmetamorphosirten Theile der Zelle eine starke Trübung, während zu gleicher Zeit der Körper, sowie der Fuss derselben stark sich anfhellen und weniger körnig werden; zugleich tritt der Kern deutlicher hervor, wird melr rundlich und schwillt an. Eben solehe Trubang des schleimig-metamorphosirten Theils tritt ein bei Einwirkung schwacher Mineralsäuren; bei Einwirkung concentrirter unorganischer Süuren erfolgt jedoch eine starke Aufhellung des metamorphosirten Theils des Protoplasma.

Schwache Lösungen von Alkalien und selbst einfacher Zusatz. 
von Wasser bewirkt starke Aufquellung. Aus diesen Reactionen lässt sich leicht erschliessen, dass der obere, scheinbar homogene Theil der Zelle nichts anderes, als eine schleimige Metamorphose des Protoplasma darstellt.

An Präparaten aus Müller'scher Flüssigkeit oder Alkohol präsentiren sich die Zellen in etwas anderer Weise. Ihr oberer metamorphosirter Theil zeigt sich entweder stark angeschwollen (s. Taf. $\mathrm{X}$, Fig. 1 und 3) oder fehlt gänzlich, so dass die Zellen wie leer erscheinen, jedoch fallen dabei die Seitencontouren der Zellenmembran, welche den oberen, schleimig metamorphosirten Theil umfassen, nicht zusammen, sondern bleiben in der Richtung zum freien Rande der Zellen hervorstehend. Bei Färbung mit Anilinblau oder Carmin nehmen der metamorphosirte Theil der Zellen und der Kern ziemlich stark den Farbstoff auf, während das Protoplasma sich bedeutend schwächer färbt, namentlich der Theil desselben, der in Art einer mehr compacten Schicht den Kern umgiebt.

Zusammen mit den am freien Ende offenen Zellen, gelang es mir bei der Katze an in indifferenten Flüssigkeiten untersuchten Präparaten auch geschlossene Epithelzellen zu beobachten, die sich nach Form und Färbung durchaus nicht von den offenen unterschieden; der obere freie Rand dieser Zellen zeigte sich deutlich doppelt contourirt. Besonders leicht konnte ich mich von letztgenanntem Umstand überzeugen, wenn ich dem Präparate einige Tropfen destillirten Wassers zusetzte, in Folge dessen der schleimig metamorphosirte Theil der Zelle schnell aufquoll und die Membran vor sich aufbuchtete, so dass die ganze Zelle die Form einer echten „Becherzelle" annahm. Später jedoch fand ich solche aufgequollene geschlossene Epithelzellen auch ohne jegliche vorläufige Bearbeitung (s. Taf. I, Fig. 2a).

Ich glaube daher, dass diejenigen Forscher (F. E. Schul ze ${ }^{1}$ ), Bleyer ${ }^{2}$ ), Biedermann ${ }^{3}$ ) u. a.), welche behaupten, dass die Epi-

1) Schulze, F. E.: „Epithel und Drüsenzellen.“ Arch. f. mikr. Anat. Bd. III. p. 174.

2) Bleyer, E.: „Magenepithel und Magendrüsen der Batrachier“. Diss. Königsberg. 1874. (Ref.: Jahresber. über d. Fortschr. d. Anatomie und Physiologie, herausg. von Hoffmann and Schwalbe. 1875. p. 209.)

3) Biedermann, W.: „Untersuchungen über das Magenepithel. Wiener Sitzungsber. LXXI. 3. p. 377-398. 
thelzellen der Magenobertäche an ihrem freien Ende immer offen seien, nicht ganz im Rechte sind. Es ist wahr, dass sich geschlossene Zellen weit seltener rorfinden als offene, und scheint mir die Ursache des Vorkommens dieser doppelten Art von Zellen entweder darin zu liegen, dass ein Cnterschied des functionellen Zustandes beider Arten vorliegt, oder was wahrscheinlicher ist, dass sich diese Zellen auf ungleicher Stufe der Entwicklung befinden, nämlich dass die am freien Ende geschlossenen Zellen jünger sind, als die offenen.

Die schleimige Metamorphose beginnt gewöhnlich unmittelbar unter der Zellmembran, im Allgemeinen vom freien Ende der Zelle her, und setzt sich gleichmässig in das Innere der Zelle fort bis zum Kerne, welcher in solchem Falle sich leicht verschoben und abgeplattet zeigt. Bei höheren Wirbelthieren habe ich selten solche Epithelien angetroffen, in denen die Anwesenheit des Kerns nicht zu constatiren gewesen wäre, so dass man schliessen könnte, dass einem vollständigen Lntergange nur wenige von den Epithelzellen anheimfallen.

Bei niederen Wirbelthieren ist die Schleimhautoberfläche bedeckt von einem Cylinderepithel, welches in Form und Charakter einigermaassen von dem eben beschriebenen abweicht. So finden sich beim Frosche zwischen den gewöhnlichen Cylinderepithelzellen mit schleimiger Metamorphose auch zerstreut sogenannte Becherzellen vor, wenngleich in sebr geringer Anzahl; ausserdem fand ich häufig Flimmerzellen.

Die Cylinderzellen (s. Taf. X, Fig. 3) erscheinen beim Frosch verhältnissmässig länger und etwas schlanker; ferner ist die Lage des Kerns verändert. In einigen Zellen ist der obere Theil, welcher den "Schleimpfropf" in sich schliesst, scharf vom Körper der Zelle abgegrenzt durch eine geringe Einziehung, in Form eines Halses, unter welchem letzteren der Kern liegt. Die Menge von Protoplasma, die den Kern umgiebt, ist äusserst gering, so dass sie sich um den Kern in Form einer feinen, bisweilen kaum bemerkbaren Zone lagert. Der Fuss der Zellen ist dagegen verhältnissmässig sehr gross und erscheint fast wie gewunden. Mitten unter diesen Zellen kommen andere vor, in welchen der Kern viel höher gelagert ist, dicht unterhalb des „Schleimpfropfes", so dass es nicht zu einer eigentlichen Einschnürung zwischen dem oberen Theil und dem Körper kommt. In Bezug auf die freie Oberfläche der Zellen, 
beobachtete ich gleich häufig offen e sowie ges chl ossene Zellen, sowohl solche mit stark ausgesprochener schleimiger Metamorphose, als auch solche, bei welchen der obere Theil körnig war und einen scharf ausgeprägten protoplasmatischen Charakter darbot, ohne die geringste Spur von schleimiger Metamorphose (s. Taf. X, Fig. 3 und 7).

Becherzellen finden sich im Magen in weit geringerer Anzahl als im Oesophagus, in welehem die Sehleimhaut fast aussehliesslich mit Becherzellen bekleidet ist. In der Form unterscheiden sich die Becherzellen des Magens von denen des Oesophagus, in welchen man, wie in Taf. X, Fig. 8 und 9 abgebildet ist, deutlich einen oberen Theil begrenzt von scharf contourirter Membran, mit homogenem, leicht mattglänzenden Inhalt, welcher Theil etwa $3 / 4$ der ganzen Zelle einnimmt und der "Theca" (Schulze) entspricht, von dem unteren protoplasmatischen Theil der Zelle trennen kann. Dieser letztere ist stark körnig und enthält gewöhnlich den ovalen Kern, welcher senkrecht zur Längsachse gestellt ist. Nicht selten sind diese Zellen mit Einschnürungen im homogenen Theile versehen, so dass letzterer birnförmig erscheint. Unter den Becherzellen der Magenschleimhaut trifft man solche Formen nicht an.

Parallel mit diesen Zellen kann man auch jüngere Formen finden, d. h. solche, wo das obere Ende, welches bei alten einen homogenen Charakter zeigt, protoplasmatisch bleibt. Diese Zellen haben eine etwas kenlenförmige Gestalt, entsprechen aber in Structur des Kerns und in ihrer Länge vollkommen den eben besehriebenen Becherzellen (s. Taf. X, Fig. 3f, g, e und Taf. X, Fig. 7.)

Flimmerzellen wurden in der Epithelschicht der Magenschleimhaut des Frosches äusserst selten angetroffen. In ihrer Form erinnern sie im Allgemeinen sebr an gewöhnliche Cylinderzellen und sind sie in der Mehrzahl der Fälle wie diese mit einem ziemlich langen, leicht verengerten Fusse versehen, selten findet man solche mit dichotomisch getheilten, protoplasmatischen Fortsätzen (s. Taf. X, Fig.6). Der Magen der Schildkröte ist ebenfalls von Cylinderepithelzellen ausgekleidet (s. Taf. X, Fig. 12a, b, c, d, e), welche sehr lang und schmal sind, einen grossen, homogenen Kern führen und einen oberen, schleimig metamorphosirten Theil zeigen. Ausserdem finden sich zwischen diesen Zellen vollkommen geschlossene vor, ohne Schleimpfiöpfe, welche sehr den „jungen" 
Becherzellen gleichen, deren verschiedene Formen von mir beim Frosche eben berïcksichtigt wurden. Bisweilen erscheinen die Zellen so dünn, dass sie den Eindruck von Fasern machen, die in der Mitte einen Kern einschliessen. Der obere Theil erscheint bei ibnen an seinem freien Ende entweder verdickt, abgerundet und ron deutlicher Membran umgeben, oder rüsselförmig (s. Taf. X, Fig. $13 \mathrm{c}$ ). Bei Tropidonotus natrix trifft man ausser dem gewöhnlichen Epithel mit schleimiger Metamorphose, welches die ganze Oberfläche des Magens rom Oesophagus an bedeckt, im Pylorustheil recht häufig auch Becherzellen an. In der Cardia und in der Fundusschleimhaut fehlen die letzteren vollständig (s. Taf. X, Fig. 14).

Bei dem letztgenannten Thiere gehen die Flimmerepithelzellen, welche den Oesophagus seiner ganzen Länge nach bekleiden, nicht auf die Magenschleimbaut über. Bei der Untersuchung der Oesophagusschleimhaut von Tropidonotus natrix fand ich unter den Becherzellen, welche in den Zwischenräumen des Cylinderepithels wie eingezwängt stehen und mit ihrem etwas verengten offenen Yündungsende die freie Oberfläche erreichen, auch solche, welche sich nicht nur oben geschlossen zeigten, sondern auch einen gut erhaltenen Saum mit Flimmerbäärchen aufiesen (s. Taf. X, Fig. 14 a).

Zu Gunsten dessen, dass man es hier mit keinem Kunstproduct zu thun hat, mit anderen Worten nicht mit dem Resultat der Aufquellung durch Wasser, spricht, dass man durch Zusatz von schwachen Essigsäurelösungen eine starke Trübung des aufgequollenen Theils der Zelle hervorrufen kann und eben dadurch die Analogie mit dem Inhalt anderer Becherzellen constatirt wird.

Ein besonderes Interesse erheischt das Epithel, welches die Magenschleimhaut bei Fischen bedeckt, sowohl seiner Form wegen, als auch desshalb, weil es in einzelnen Stücken abweicht vom Bau der Epithelzellen der Magenoberfläche bei höheren Thieren.

Bei den Fischen, welche einen Magen besitzen (Perca fluviatilis, Esox lucius u. a.) wird das Flimmerepithel, welches in fast ununterbrochener Schicht den ganzen Oesophagus bekleidet, beim Uebergang auf die Magenschleimhaut durch gewöhnliches Cylinderepithel mit schleimiger Metamorphose am freien Ende der Zellen ersetzt. Zwischen den Cylinderzelien treffen wir jedoch auch Flimmerzellen in grosser Anzahl an, ununterbrochen bis zum Pylorus 
reichend. Sowohl die cylindrischen Flimmerzellen, als auch dit Zellen mit schleimiger Metamorphose zeigen sich ungewöhnlich hoch und schmal, enthalten einen grossen, ovalen oder runden Kern; mit ihrem unteren Theile setzen sie sich in einen sebr langen, fadenartigen Fortsatz fort, welcher in seinem weiteren Verlauf ein bis zwei varicöse Anschwellungen zeigt, in Form von glänzenden, glasartigen, stark lichtbrechenden Verdickungen. Bisweilen gelingt es, in einer solchen varicösen Verdickung etwas einem Kern ähnliches zu entdecken, gewöhnlich aber bringen die Verdickungen eher den Eindruck eines stärker sclerosirten Theil des Fortsatzes hervor (s. Taf. X, Fig. 5).

Durch diese Fortsätze verflechten sich die Zellen unter einander, so dass es zu guter Letzt fast unmöglich wird, die Richtung dieser Fortsätze zu bestimmen. Ungeachtet aller Bemühungen, diese Gebilde genauer zu studiren, welche im Verlauf der Zellenausläufer sich vorfinden, konnte ich $\mathrm{zu}$ keinem befriedigenden Resultate kommen.

Fussend auf den Beobachtungen von Fr. E. Schulze, welcher geneigt ist, diesen Fortsätzen einen nervösen Charakter zuzuschreiben, versuchte ich dieselben mit Osmiumsäure zu färben und die Reaction von Schwefelsäure und Jod zu erproben, in der Hoffnung, vielleicht Spuren von Zerfall der Nervensubstanz zu finden, jedoch ohne Erfolg. Bei Färbung mit gewöhnlichen Farbstoffen (Carmin, Anilin, Eosin) farbten sich die Verdickungen selbst am wenigsten oder färbten sich überha upt gar nicht.

Resiimirt man alles tiber die Epithelzellen, welche die Oberfläche der Magenschleimhaut bei verschiedenen Thieren bedecken, Gesagte, so kommt man zu dem Schluss, dass die Hauptbestimmung: dieser Elemente die Schleimabsonderung ist, welche bei Säugern durch eine Art von Zellen bewirkt wird; bei anderen, mehr niederen Thieren theilt diese Function noch eine andere Art von Zellen, nämlich die Becherzellen. Stellt man indessen beide Arten von Zellen nebeneinander und vergleicht ihre verschiedenen Formveränderungen, so überzeugt man sich leicht von der Existenz einer ganzen Reibe von Uebergangsformen von gewöhnlichen Cylinderzellen mit geringfiigiger schleimiger Metamorphose, wie dies bei len Säugern beobachtet wird, zu echten sogenannten „Becherzellen", welche sich bei niederen Thieren in grosser Anzall. in ler Schleimbaut des Oesophagus vorfinden, aber auch in der Ma- 
genschleimhaut besagter Thiere nicht fehlen. Der ganze Unterschied zwischen den einen und den anderen Zellen beschränkt sich darauf, dass bei einiren Thieren die schleimige Metamorphose nicht so intensiv ausgeprägt ist und nur einen geringen Theil des Zellprotoplasma ergreift, bei anderen Zellen dagegen weit stärker auftritt und zur Schleimbildung eine grössere Menge von Protoplasma verbraucht, wie solches in den Becherzellen stattfindet. Der Befund von Flimmerzellen im Epithel der Magensehleimhaut kann, nach meiner Ansicht, benutzt werden zur Entscheidung einiger Streitpunkte betretis der genetischen Verbindung und des gegenseitigen Verhältnisses der Elemente, welche die epitheliale Bedeckung der Magenschleimhant und die Schleimbaut des übrigen Darmtraetus zusammensetzen.

Schon der Umstand allein, dass Flimmerzellen bei der Mehrzahl von Thieren nur in äusserst geringer Anzahl vorkommen, erlanbt uns, den Flimmerzellen irgend welche wichtige Bedeutung für die Function der Magrenschleimhaut abzusprechen und veranlasst uns, dieselben als residuale Gebildeder Embryonalperiode zu betrachten.

Ferner bestätigt der Befund von Becherzellen mit Flimmerhäärchen gewissermaassen unsere Ansicht in Betreff der identischen Natur von Cylinderepithel und „Becherzellen".

Wie aus den jüngsten Arbeiten von Regeczy), Braun ${ }^{2}$ ) und Blanchard ${ }^{3}$ ) bekannt ist, wurde häufig das Factum constatirt, dass in der Magenschleimhaut sich vereinzelt Flimmerepithelzellen vorfinden. Ohne den Angaben dieser Forscher widersprechen zu wollen, bemerke ich, dass, wenn die Auffindung von Flimmerepithel mit grossen Schwierigkeiten verbunden ist und zu versehiedenen Resultaten führt, dieses sich durch die Unbeständigkeit im Vorhandensein von Flimmerzellen in der Magenschleimhaut erklären lässt, oder zum wenigsten, dass sich Flimmerepithel in äusserst geringer Menge vorfindet.

1) v. Regeczy u. E. Sagy: „Ueber die Epithelzellen des Magens". Arch. f. mikr. Anat. Bd. 1S. Heft t. 1880. p. 408.

2) Braun, M.: „Zum Vorkommen von Flimmerepithel im Magen". Zool. Anzeiger 69. 1850.

3) Blanchard, R: „:Sur la présence de l'épithelium vibratile dans l'intestin". Zool. Anzeiger. 1880. 72. p. 67. 
Dieses seltene Vorkommen hat auch einen gewissen Grund darin, dass ïberhaupt, wie aus den Beobachtungen vieler Forscher (Klein ${ }^{1}$, Neumann ${ }^{2}$ ), Langerhans ${ }^{3}$ ) u. a.) hervorgeht, Flimmerepithel an solchen Schleimbüuten angetroffen wird, welche ein neutrales oder alcalisches Secret liefern. Ich glaube, dass aller Wahrscheinlichkeit nach im vorliegenden Falle das saure Secret der Magenschleimhaut ein sehr ungünstiges Medium für die Existenz von Flimmerzellen abgiebt. Man darf sich nur an die unmittelbare Beobachtung erinnern, dass überhaupt Zusatz von Säuren (resp. sauren Magensaft) die Flimmerbewegung verlangsamt, noch häufiger dieselbe ganz aufhebt. Im Gegentheil ist in der Embryonalperiode, bei einigen Fischen und einigen anderen niederen Thieren, welehe kein eigentlich saures Magensecret haben, der ganze Darmtractus ausschliesslich mit Flimmerepithel bekleidet. Anderseits erklärt die Anwesenheit von Flimmerepithel in der Magensehleimhaut bis zu einem gewissen Grade den Ursprung anderer Formen von Epithelzellen, welche die Schleimhaut des übrigen Theils von Darmtractus bekleidet, ich meine im vorliegenden Falle das Epithel der Darmzotten. Die Ansicht von Prof. Kutschin, welche er schon lange in seinen Vorlesungen über Histologie ausgesprochen hat, dass man die Stäbchen der Zottenepitbelzellen als metamorphosirte Flimmerhäärchen zn betrachten habe, findet offenbar eine gute Stiitze durch den Befund von Flimmerepithel in der Magenschleimhaut.

Unmittelbar unter dem Epithel der Oberfläche oder zwischen dem unteren Ende seiner Zellen kann man in der Mehrzahl der Fälle besondere Gebilde beobachten, von rundlicher, ovaler oder etwas eckiger Form, welche nichts anderes darstellen, als junge Zellen von protoplasmatischem Charakter. Mit ihrem leicht zugeschärften Ende liegen sie (s. Taf.X, Fig. 11g und Fig. 15a-b) gewöhnlich zwischen den Füssen zweier benachbarter Cylinderzellen, werden von letzteren oft ganz umfasst und dann stellen sie

1) Klein: „On the ciliated epithelium of the oesophagus (Quart. Journal of mikroskop. Science. Vol. XX. p. 476).

2) Neumann, E.: „Flimmerepithel im Oesophagus menschlicher Embryonen". Arch. f. mikr. Anat. Bd. XII. p. 57.

3) Langerhans, P.: „Untersuch. über Petromyzon Planeri“. Ref. Scbwalbe's Jahresber. Bd. II. 1873. p. 193. 
sich nicht in Form ron conischen Zellen dar, sondern haben eher eine rundliche Form. An Zupfpräparaten aus Müller'scher Flüssigkeit trifft man sehr hänfig zwischen den unteren Enden der cylindrischen Epithelzellen leere, rundliche Löcher (s. Taf. X, Fig. 15 b) die auf die Stellen, wo diese Zellen herausgefallen sind, hinweisen. Das Protoplasma dieser Zellen, welche schon von Todd, Bowman, alsdann von Watney unter dem Namen von „epithelial buds" beschrieben wurden und von Ebstein als "Ersatzzellen" anerkannt worden sind, ist feinkörnig, bisweilen fast homogen und enthält einen grossen runden Kern. Bei Färbung durch Eosin erscheinen diese Zellen etwas blasser als die über ihnen gelagerten Cylinderzellen und unterscheiden sich daber ziemlich scharf von denselben.

Besonders gut konnte ich die Ersatzzellen an der Magenschleimhaut von Emys europaea studiren, bei welcher im oberflächlichen Epithel die schleimige Metamorphose sehr deutlich ausgeprägt ist, und wo man sich dem Anscheine nach am klarsten von der Bestimmung dieser Zellen überzeugen kann (s. Taf. X, Fig. 13a b). Abgesehen daron, dass ich bei diesem Thiere die Ersatzzellen in ansehnlicher Zahl fand, wiesen dieselben grösstentheils sehr charakteristische Umrisse auf; sie nehmen bisweilen eine spindelförmige Gestalt an, enthalten zwei deutlich doppelt-contourirte Kerne und werden häufig in Gruppen angetroffen.

Ehe ich zur Beschreibung der auf das Epithel der Magenoberfläche folgenden Drüsenschicht and des Stroma der Schleimhaut übergehe, werle ich noch auf eine Entdeckung kurz eingehen, welche schon $D$ ebove ${ }^{1}$ ) beim Studium der Schleimhänte machte, welche jedoch von andern Forschern wie Forster ${ }^{2}$ ) und Tourneax ${ }^{3}$ ) nicht bestätigt wurde. Debove beschreibt eine besondere Lage, "subepitheliale" von ihm genannt, welche unmittelbar dem oberflächlichen Epithel anliegt und welche aus grossen, kernlosen Zellen bestehen sollte. Was mich anbetrifft, so habe ich bei der Bearbeitungsmethode, welche Debove empfiehlt (Versilberung 1/300 arg. nitrici, Abspülen mit dem Pinsel und nochmalige Versilberung) ungeachtet mehrmaliger Ver-

1) Debove, M: :Mémoire sur la couche endotheliale sousépithéliale des membranes muqueuses: Arch. de physiol. p. 19-26.

2) Forster, M.: „On the term endothelium". Quart. Journal of microsc. science p. $219-223$.

3) Tourneux, Fr.: „Recherches sur l'épithelium des sereuses" Robin journ. de l'anat. etc. p. 66-83. Chap. XII, 11. 
silberung, welche ich zu diesem Zwecke vornahm, an der Schleimhaut bei Ratte und Maus keine Billder erlangen können, die mit seinen Angaben stimmten.

Bei der Ratte trifft man nach „doppelter Versilberung" und nachfolgender Färbung durch Hämatoxylin allerdings einzelne Gruppen von Zellen, welche unmittelbar unter der oberflächlichen Epithelschicht liegen. Diese Zellen haben sehr grosse Aehnlichkeit mit endothelialen Plättchen, erscheinen platt, glasartig, unregelmässig eckig, sehr dünn mit deutlich hervorspringendem Kern, der von einer schmalen Zone von körnigem Protoplasma umgeben ist. Ein gïnstiges Objekt zur Untersuchung in dieser Beziehung bietet auch die Magenschleimhaut einiger Fische. In Isolationspräparaten (Bars) aus Müll. Flüssigkeit oder aus Lösungen von doppelchromsaurem Kali trifft man nach vorsichtigem Zerzupfen zwischen den Cylinder- und Becherzellen, Zellen an, welche entweder vereinzelt oder in Gruppen von 3-4-5 umherschwimmen, und welche einen vollkommen endothelialen Charakter tragen. Ihre Form ist gewöhnlich unregelmässig viereckig und sind sie mit einem deutlich faserigen Kern versehen; eine solche fasrige Structur zeigt auch das Protoplasma der Zellen. Feine Fädchen, die in nächster Nähe des Kernes scheinbar ihren Anfang nehmen, setzen sich fort bis zu den vorragendsten Winkeln der Zelle und nachdem sie an diesen Stellen sich umbiegen, laufen dieselben parallel den peripherischen Theilen der Zelle, um an den entgegengesetzten Winkeln, von neuem einige Windungen machend, sich wieder dem Kerne zu nähern. In Betreff des Fädchennetzes im Kerne sieht man, dass an vielen Stellen die Fädchen sich miteinander kreuzen, wobei sie unbedeutende Verdickungen oder Knötchen zu bilden scheinen, welche den Eindruck von glänzenden Körnchen machen (s. Taf. X, Fig. 16 u. 17).

Bei anderen Thieren und hauptsächlich bei den höheren Säugern habe ich etwas dieser subepithelialen Schicht Aehnliches beobachtet; ich halte es für wahrscheinlich, dass diese Schicht, welche Debove für eine besondere Lage hält, nichts anderes ist, als der mehr lockere junge Theil der Membrana propria der Drüsen, wo die Zellen noch nicht genügend dem Sclerosirungsprocess unterworfen sind und noch keine homogene Lage bilden; sie bilden jedoch eine Art von durchlöcherter oder gefensterter Membran, die zwischen den Drüsentrichtern ausgespannt ist und welche in Verbindung mit den Elementen, welche die Propria der Drüsenröhrchen bilden, zu stehen scheint.

Die Drüsen, welche die Schleimhaut des Magens beherbergt, sind bei fast allen Thieren ohne Ausnahme nach dem Typas einfacher Röhrendrüseu geformt und nur ein geringer Theil von Drüsen in einigen Abtheilungen des Magens trägt einen mehr acinösen Charakter.

Indem ich mich der Terminologie Heidenhain's anschliesse, unterseheide ich an den Drüsen folgẹnde drei Haupttheile, die bei 
den Drüsen fast aller Thiere genïgend ausgeprägt sind: Ausgang, Hals und Körper. Der obere Theil ist der trichterförmig erweiterte Ausgang der Drüsenröbre, der sich wie eine gemeinsame Mündung für einige Drtisenröhrchen ausnimmt und an seinem unteren, etwas verengten Theile in den sogenannten Hals ibergeht. Dieser letztgenaunte Theil des Drüsenröhrchens erscheint als der engste von allen Abtlieilungen der Drüse. Der unterste und zugleich bauptsächlichste Theil der Drüsen, ihr Körper, stösst oben unmittelbar an den Hals, nach unten erweitert er sich entweder allmählich oder schwillt kolbig an und endet blind. Sowohl die Länge, als auch der Durchmesser der einzelnen Theile ändert sich je nach der Thierspecies; aber auch an den verschiedenen Stellen der Schleimhaut; in dieser Beziehung zeigt die grössten Schwankungen der Ausgangstrichter und der Körper der Drüsenröhrchen, während der Hals derselben in allen Fällen den engsten Durchmesser beibehält und von allen Theilen der Drüse am wenigsten Veränderungen aufweist. Die Länge der Drüsen und ibre Lage in Bezug auf die Oberfläche der Schleimbant, als auch in Bezug auf ihre gegenseitige Lage zu einander wird gleicher Weise bedingt nicht allein durch die verschiedene Stelle und durch die Verschiedenheit in der Structur der darunter liegenden 'lbeile, von welchen auch die Configuration der Drüsen selbst abhängt, sondern auch von Verschiedenbeiten, welche jeder einzelnen Thierspecies eigenthümlich sind und wahrscheinlich auch von einem gewissen Unterschiede in der Function. Den Ausgangstheil der Drüsen oder den Trichter, wie ich ihn nennen werde, kann man als eine einfache Ausstulpung von Seiten der Schleimhant her betrachten. Das einschichtige, schleimig metamorphosirte cylindrische Epithel der Oberfläche setzt sich unmittelbar und ohne sichtbare Veränderung auf den Trichter fort, wobei im oberen Theil desselben die Epithelzellen unregelmässig gebogen erscheinen und sich mit ihren verlängerten dünnen Fortsätzen eng verlöthen; dieselben zeigen längliche, etwas ausgezogene Kerne.

Gegen den Grund des Trichters hin werden die Zellen bedeutend kürzer, sind nicht mehr spitzwinklig gegen die Längsachse des Röhrchens gelagert, sondern stehen mehr oder weniger senkrecht zur membrana propria. Am Grunde' des Trichters zeigen sich die Zellen vollkommen geschlossen, enthalten einen mehr runden Kern, werden körniger und färben sich etwas intensiver, 
als die höher liegenden Cylinderzellen. Das ist eine in allgemeinen Umrissen gegebene Beschreibung der Elemente, welche den eigentlichen Trichter auskleiden.

Was den Drüsenbals anbetrifft, so erscheint er an Präparaten, welche mit Carmin oder Anilin gefürbt wordèn waren, bei geringer Vergrösserung betrachtet, von rundlichen, intensiv gefärbten Zellen erfült. Es ist zu bemerken, dass dieser Drüsentheil, sowie das obere Ende des Drüsenkörpers im Vergleich mit den übrigen Abtheilungen des Drüsenröhrchens, sich im Allgemeinen an den Fräparaten immer am intensivsten gefärbt erweisen.

Ein genaueres Studium der Elemente, sowohl an Längsschnitten, als auch an aufeinander folgenden Querschnitten, zeigt jedoch, dass gerade dieser Theil der Drüse in seiner Structur fast der allercomplicirteste ist. In Bezug auf Schwierigkeit des Studiums der ihn zusammensetzenden Elemente gebührt ihm der erste Platz. Die Erforschung wird theils erschwert durch die bisweilen geringe Ausdehnung des ebengenannten Theils, theils durch die schwach markirte Abgrenzung zwischen Drüsenhals einerseits und Drüsenkörper anderseits. Eine genauere Beschreibung wird jedoch am besten erst nach Besprechung des Drüsenkörpers gegeben.

Bei allen höheren Wirbelthieren ist, wie das seit den Untersuchunger Heidenhain's und Rollett's bekannt worden, der Körper aller Fundus- und Cardiadrüsen mit einer doppelten Art von Zellen ausgekleidet. Die einen von diesen Zellen (Beleg- oder delomorphe Zellen), von grösserem Umfang und stärker körnig, weisen eine unregelmässig winklige oder ovale Form auf und liegen in der ganzen Ausdehnung des Drüsenkörpers zwischen der Membrana propria und einer Schicht der anderen Art von Zellen (Haupt- oder adelomorphe Zellen), welche von geringer Grösse, von conischer oder cylindrischer Form sind und nach innen von den ersteren gelegen, in ununterbrochener Schicht das Lumen der Röhrchen auskleiden und begrenzen.

Bei Hund und Katze erscheinen die frisch in humor aquaeus untersuchten Drïsen dem Ansehen nach als fast homogene feinkörnige Röhrchen von graulich-weisser oder leicht gelblicher Farbe. Trotzdem zeichnen sich die äusseren Contouren der Drüsen ziemlich deutlich ab und dieselben erscheinen nicht selten etwas höckerig, wie wellenförmig begrenzt. Letztere Form des Contours entspricht der Lagerung der Belegzellen, welche, da sie iberhaupt 
unmittelbar unter der Membrana propria liegen, letztere ausbuchten und den Eindruck von Erhöhungen hervorbringen, welche man am Contour der Driisen bemerkt. (s. Taf. X, Fig. 18).

Die ganze Drüse erscheint stark körnig und die Grenzen zwischen den einzelnen Zellen treten nicht hervor, jedoch lassen sich die einzelnen Belegzellen in Form von mehr helleren Feldern erkennen; die Zwischenräume zwischen diesen Feldern, welche der Lage der Hauptzellen entsprechen, erscheinen dunkler; Zusatz einer geringen Menge von destillirtem Wasser ruft eine bedeutende Aufquellung der Belegzellen hervor. Die Contouren derselben werden deutlicher, das Protoplasma körniger und deshalb treten die Zellen schärfer hervor; die Aufhellung der Hauptzellen geht weit langsamer vor sich. Nach Verlauf einiger Zeit bei fortdauernder Einwirkung von Wasser nehmen die Drüsen ein ganz anderes Ansehen an: während an Stelle der friber undeutlich begrenzten helleren Felder jetzt scharf begrenzte, grobkörnige und kernhaltige Belegzellen auftreten, "sind die Grenzen zwischen den einzelnen Hauptzellen noch nicht sichtbar, man findet dagegen nur eine mattglänzende, homogene, zartkörnige Masse, wo auch keine Kerne zu entdecken sind.

Bei Einwirkung von Aetzalcalien in ziemlich concentrirten Lösungen (35\%) werden die Grenzen zwischen den einzelnen Belegund Hauptzellen so scharf, dass sowohl die Form, als auch die Lage beider Zellenarten auf das Deutlichste sichtbar werden. Das Protoplasma sowohl der Beleg- als der Hauptzellen wird stark aufgehellt. Die Belegzellen springen an den Seiten der Drïse stark hervor. Die Kerne, welche bis dahin wegen der starken Körnelung des sie umgebenden Protoplasma schwach sichtbar waren, erhalten einen deutlichen Contour und nehmen, allmählich anschwellend, endlich ein bläschenartiges Ansehen an.

Schwache Lösungen von Essigsäure $(0,5-1 \%)$ wirken etwas verschieden auf Haupt- und Belegzellen ein. Letztere hellen sich stark auf, werden feinkörnig und erhalten wie einen verdickten peripherischen Contour; der Kern quillt stark anf und wird homogen. Obgleich nun auch die Contouren der Hauptzellen ebenfalls schärfer werden, so bemerkt man im Protoplasma derselben eine Trubung, die Zellen scheinen etwas zu schrumpfen und sich zu runzeln, so dass der Kern unbemerkbar wird.

Anwendung schwacher Lösungen von Mineralsäuren (bis $0,05 \%$ ), 
nämlich von Salpeter- und Salzsäure, bewirkt starkes Aufquellen und Aufhellen der Belegzellen, deren Protoplasma sehr schwachkörnig wird; die Contouren treten dagegen wie auch bei Einwirkung von Essigsäure, sehr scharf hervor. Die Kerne schwellen ebenfalls an, werden durchsichtig, glasartig, rundlich und erscheinen nicht selten doppelt contourirt. Was die Hauptzellen anbetrifft, so treten die Grenzen zwischen denselben ebenfalls ziemlich scharf hervor. Die Zellen erscheinen dunkler und schrumpfen schliesslich zusammen. Unter dem Einfluss stärkerer Lösungen von Mineralsäuren $(0,5-1 \%)$ tritt bedeutendere Trübung und Schrumpfung beider Zellenarten ein. Dem Auge erscheint das Protoplasma, besonders in den Belegzellen, wie an einzelnen Stellen geronnen, die Zellencontouren zeigen sich gezackt, die Kerne runzeln sich und schrumpfen zusammen und heben sich an ihrer Peripherie nicht deutlich von der sie umgebenden Protoplasmazone ab.

Concentrirte Salzlösungen (ClNa) rufen in beiderlei Arten von Zellen eine starke Sehrumpfung hervor. In den Belegzellen erscheinen die Kerne, wie zur Peripherie verrückt, leicht gezackt, rosettenförmig und wie zerknittert. In Folge dieser Schrumpfung erscheinen die Belegzellen mehr von der Membrana propria abgerïckt. Nach allen oben angeführten Reactionen, welche an den Zellen beider Arten bemerkt werden, kann man an der eiweissartigen Natur dieser Zellen nicht zweifeln, nichts desto weniger ist die Vertheilung der Eiweisspartikel in den Haupt- und Belegzellen eine etwas andere.

Dieser Unterschied tritt am Deatlichsten, wie wir oben gesehen, bei Einwirkung von Essigsäure, aber auch bei schwachen Mineralsäuren auf, wo in den Belegzellen eine Art von Verflussigung oder Aufhellung der Eiweissmolecuile, welche das Zellprotoplasma zusammensetzen, sich beobachten lässt, während zu gleicher Zeit in den Hauptzellen eine gewisse Trübung eintritt. Diese letztere Erscheinung beruht augenscheinlich auf der Anwesenheit einer gewissen Menge von Mucin im Protoplasma der Hauptzellen, oder eines mucinähnlichen Stoffes, welchen man als ein Derivat des Zellprotoplasma betrachten kann. Nach den Reactionen zu urtheilen, zeigt sich diese Substanz (Mucin) ausschliesslich in den Hauptzellen als höher differenzirten Zellen und folglich in höherem Grade geeigneten eine bedeutende Menge solcher Stoffe zu liefern, welche als Pro- 
ducte einer regressiven Metamorphose anzusehen w äre n.

In den Belegzellen trägt das Protoplasma einen ausschliesslich eiweissartigen Charakter.

Die Belegzellen der höheren Wirbelthiere im isolirten Zustande und in möglichst indifferenten Medien (Humor aquaeus, Jodscrum, ClNa) untersucht, stellen Zellen von grosser, ovaler, unregelmässig eckiger Form dar, welche bisweilen eine viereckige und leicht oval abgerundete Gestalt annehmen. Sie haben einen vollkommen protoplasmatischen Charakter und erweisen sich ungeachtet ihres grossen Körnchenreichthums sehr durchscheinend. Der runde, doppelt contourirte Kern liegt meistens im Centrum und enthält ein oder zwei Kernkörperchen; doch trifft man auch Zellen mit etwas excentrischem Kern an. Der Theil des Zellkörpers im Gebiete des Kernes erscheint gewöhnlich etwas dicker. Wenn man die Zellen in den verschiedenen Flächenansichten betrachtet, kann man bemerken, dass viele von ihnen nach der Mitte zu wie leicht eingedrückt erscheinen, was den Zellen die Form von Dachziegeln verleiht.

Ausser diesen Formen werden Zellen angetroffen, welche noch einen mehr deutlich ausgesprochenen protoplasmatischen Charakter tragen. Eine häufig anzutreffende Zellform (Katze, Hund) ist die unregelmässig dreieckige. Solche Zellen zeigen sich an einem ibrer freien Ende in einen nicht grossen, bisweilen leicht zugeschärften Fortsatz ausgezogen. An ibnen springt besonders in die Augen die ungleichmässige Vertheilung der Körnchen und eine gewisse Eigenthümlichkeit in der ungleichen Dicke des Körpers. Der breitere, halbovale Theil der Zelle, welcher den Kern einschliesst, erscheint stark körnig, dunkel, mit ziemlich scharfem äusseren Contour. In dem verengerten fortsatzförmigen Theile ist das Protoplasma bedeutend feinkörniger und hat sogar einen gleichartigen, homogenen Charakter. Der Unterschied zwischen dem schmaleren und breiteren Theile tritt noch deutlicher hervor nach Einwirkung gewisser Reagentien, z. B. bei Einwirkung von acid. acet. $(0,6-1 \%)$. Nicht selten bei starker Aufhellung des körnigen Theils bleibt der verlängerte Theil der Zelle ohne jegliehe Veränderung, grösstentheils beobachtet man aber, dass bei der Aufhellnng und dem Aufquellen der Basis der mehr homogene Fortsatz wohl nicht aufquillt, jedoch dunkler, trüber und körniger wird. 
Bei einigen Nagern, besonders bei Maus und Ratte sind alle Belegzellen mit Fortsätzen versehen. Ihrer Form nach erscheinen diese Zellen sehr variabel, was deutlich aus den Abbildungen (s. Taf. XI, Fig. 2 u. 3) zu ersehen ist. Sie erscheinen stark körnig. Der runde Kern, von bedeutenden Dimensionen, liegt gewöhnlich im Centrum des Zellleibes.

Das Studium der Hauptzellen in isolirtem Zustande, besonders frisch, ist mit vielen Schwierigkeiten verknüpft, was zum Theil davon abbängt, dass dieselben nur mit Mühe zu isoliren sind. An Präparaten aus Jodserum und solchen aus starken alkalischen Lösungen erscheinen dieselben von conischer, kegelartiger oder annähernd cylindrischer Form, mit abgesetzter Spitze nnd verhältnissmässig breiter Basis. Der blasse, aber meistentheils deutlich doppelt contourirte Kern ist im breiten Theil der Zelle gelagert, hat häufig eine runde oder etwas verlängerte Form und liegt im letzten Falle quer zur Längsaxe der Zelle. Das Zellenprotoplasma erscheint sehr zartkörnig, fast homogen und ist bedeutend blasser als das Protoplasma der Belegzellen unter denselben Umständen.

An Schnitten aus Alkoholpräparaten mit Carmin oder Anilin (Heidenhain's Methode) tingirt, tritt der relative Unterschied zwischen Beleg- und Hauptzellen am deutlichsten hervor: während die Belegzellen dichter im oberen Theil des Drüsenkörpers angehäuft, im unteren Theil desselben aber mehr zerstreut, sich intensiv gefärbt zeigen, haben die Hauptzellen ein blasses Aussehen und erscheinen ganz ungefärbt (s. Taf. XI, Fig. 5).

Es versteht sich von selbst, dass die gegenseitigen Lageverhältnisse der Beleg- und Hauptzellen zu einander, sowie zu den übrigen Theilen der Drüse, nämlich ihre Lage zur Membrana propria und zum Lumen derselben am Bequemsten an Quersehnitten zu studiren sind. Ohne in eine zu genaue Beschreibung dieser Verhältnisse einzugehen, verweise ich den Leser auf die betreffenden Abbildungen (s. Taf. XI, Fig. 10 u. 11).

Ich bemerke nur, dass an feinen Schnittpräparaten die verschiedenen Formen von Belegzellen anch dadurch hervorgebracht werden, dass ein grösserer oder kleinerer Theil des Zellkörpers weggeschnitten ist. In solchem Falle erinnern die Belegzellen ihrer geringen Grösse und ihrer Lage nach an die sogenannten Gian nuzi'schen Halbmonde der Speicheldrisen (s. Taf. XI, Fig. $7 \mathrm{c}$ ).

Die häufigste Lage der Belegzellen ist diejenige, bei welcher 
sie in dreieckiger Form erscheinen, mit etwas zugeschärften fortsatzähnlichen Enden, welche nach dem Lumen der Drüse hin gerichtet sind. Der zugeschärfte Theil der Zellen erscheint unvergleichlich blasser und weniger körnig, ja, vollkommen homogen und glasartig, während der abrige Theil, welcher der Membrana propria anliegt oder zwischen derselben und den Basen der Hauptzellen liegt, stark körnig ist. Es ist zu erwähnen, dass dieser hellere Theil der Zellen auch viel weniger färbbar ist, was schon Stöhr richtig bemerkt hat.

Ob die Belegzellen an der Begrenzung des Drüsenlumens Antheil nehmen, ist noch eine nicht ganz entschiedene Frage. Man trifft nicht selten auf Belegzellen, die zwischen den cylindrischen Zellen hindurch bis zum Lumen dringen, aber dass alle Belegzellen das Lumen erreichen, wie das $S$ tö $h r^{1}$ ) und zum Theil auch Edinger ${ }^{2}$ ) meinen, davon konnte ich mich nicht genügend überzeugen.

An Präparaten jedoch, nach der Heidenhain'schen Methode gefärbt, erhält man doch nicht immer die gleichen Bilder: nicht in allen Fällen sind nur die Belegzellen blan oder roth gefärbt, sondern auch viele von den Hauptzellen haben den Farbstoff angenommen, anderseits sind auch Belegzellen zu finden, die blass erscheinen und nur sehr schwach tingirt sind (s. Taf.XI, Fig.. 5).

Da Zellen, welche einen scharf ausgesprochenen albuminösen Charakter tragen und für solche muss man ohne Zweifel die Belegzellen halten, sich am intensivsten durch Anilinfarben und durch Carmin färben, so muss man glauben, dass auch intensiv gefärbte Hauptzellen sich von den übrigen durch den grösseren Reichthum an Eiweissstoffen unterscheiden. Nicht selten habe ich auch solche Zellformen getroffen, die ihrer Form und Lage nach vollständig den Hauptzellen entsprachen, ihrer Färbung und Körnerreichthum uach an Belegzellen erinnerten (s. Taf. XI, Fig. 7a).

Auf solche Weise kommen wir zu dem Schlusse, dass zwischen Haupt- und Belegzellen eine Reihe von Uebergangsstufen oder Uebergangsformen vorhanden sind. Solche Formen beobachtet man nicht nur an Anilin-, Carmin-, son-

1) Stöhr, Ph.: „Zur Kenntniss des feineren Baues der Magenschleimhaut. Arch. f. mikr. Anat. Bd. XX. p. 221-245. 1881.

2) Edinger: „Zur Kenntniss der Drüsenzellen des Magens, besonders beim Menschen". Arch. f. mikr. Anat. Bd. XViII. pag. 193. 
dern auch an Eosin- und Hämatoxylin-Schnittpräparaten. Nicht weniger deutlich treten sie auch an in Osmiumsïure erbärteten Magenschleimhäuten verschiedener Säugethiere hervor. Somit wäre ich auch in Uebereinstimmung mit $\operatorname{Orth}^{1 j}$ und Edinger, die ebenfalls Uebergangsformen zwischen beiderlei Arten von Zellen der Magendrtisen annehmen, nur mit dem Unterschiede, dass meiner Meinung nach Hauptzellen aus Belegzellen entstehen, während die genannten Forscher umgekehrt einen Uebergang von Haupt- zú Belegzellen behaupten. Man vergleiche hierza noch die Angaben von Stöhr l. c. und Told $t^{2}$ ).

Die von uns gegebene Darstellung der Drüsen und ihrer Formelemente bezog sich auf hungernde Thiere. Während des Verdaungsactes ändert sich das äussere Aussehen der Drüse sowohl, wie auch das der Haupt- und Belegzellen bedeutend. Diese Veränderungen lassen sich auf Folgendes zurückfübren: Während die Drtisen hungernder Thiere sich wie zusammengefallen ausnehmen, sich schmal und lang zeigen, obne wellenförmige Contouren, erweisen sich die der verdauenden Thiere verkürzt, aber daful in ihrem Querdurchmesser vergrössert und mit unebenen, höckerigen Contouren versehen (s. Taf. $\mathrm{X}$, Fig. $18 \mathrm{a}-\mathrm{b}$ ).

Die Hauptzellen, welche bisher blass erschienen und fast gar keine Farbstoffe aufnahmen, sind jetzt an Umfang vergrössert, mit weniger scharfen Contonren und zeigen nicht so winklige Umrisse.

Ihr Protoplasma ist mit feinen und groben durch Anilin und Carmin sich färbenden Körnern durchsetzt, wodurch die Zellen dunkler und etwas intensiver gefärbt auftreten. Die Kerne nehmen an Grösse zu, färben sich intensiver und treten dadurch auch schärfer hervor. Eine solche Aufquellung und Trubung der adelomorphen Zelten ist am deutlichsten 4-8 Stunden nach Anfang der Verdauung ausgeprägt.

Bei Mäusen und Ratten ist es mir niemals gelungen, deutliche mikroskopische Unterschiede im Aussehen der ruhenden und thätigen Magendrüsen zu constatiren. Die Drüsen befinden sich in dem Zustande, welcher bei andern Thieren nur der Periode der Verdauung eigen ist.

In den funktionirenden Drüsen zeigen die Belegzellen nicht weniger wichtige Veränderungen. Während in ruhenden Drtisen

1) Orth, J.: Handbuch d. norm. Histologie. 1881. pag. 182. (russisch).

2) Toldt, Die Entwicklung und Ausbildung der Drüsen des Magens. Wiener akad. Sitzungsber. III. Abth. 82 Bd. Juli 1880. 
dieselben in ziemlich regelmässigen Längsreihen angeordnet liegen, liegen sie in thätigen Drüsen dicht und unregelmässig neben einander, so dass die Hauptzellen von ihnen ganz verdeckt werden.

Die Belegzellen stellen sich stark aufgequollen dar und von mehr runder Fórm, während in den ruhenden Drüsen dieselben mehr eckig und langgestreckt erseheinen. Das Protoplasma wird grob- und reichkörniger. Als bedeutendste und wichtigste Veränderung der Belegzellen der im thätigen Zustande sich befindenden Magendrüsen müssen wir die Vermehrungserscheinungen derselben betrachten, die in den faserigen Metamorphosen i hrer Kerne sich äussern. Die sehr kleinen Belegzellen, welche man nicht selten an der Seite der viel grösseren antrifft, glaube ich berechtigt zu sein als junge eben durch Theilung entstandene Formen aufzufassen (s. Taf. XI, Fig. 1n-l).

Das Protoplasma der jungen Zellen erscheint stark körnig und die Zone desselben, welche um den Kern gelagert ist, enthält gröbere Körner.

An Querschnitten kann man sich leicht davon tiberzeugen, dass die doppelkernigen Zellen durchaus nicht in so geringer Menge vorkommen, um denselben nicht eine wichtigere Bedeutung beizulegen und mehr Aufmerksamkeit auf diesen Umstand zu wenden, als bis jetzt geschehen ist (s. Taf. XI).

Zieht man nun das Factum in Betracht, dass im Gegensatz zu den Belegzellen in den Hauptzellen ausser einer geringfïgigen Anschwellung sich keine anderen Veränderungen bemerkbar machen, welche auf eine Vermehrung derselben hinweisen, so kommt man zu dem Schlusse, dass die Belegzellen sich während des Verdaungsaktes vermehren und die entstandenenjungen Zellformen allmählich gegen das Lumen der Drüse rỉcken, sich in Hauptzellen verwandeln und a uf diese Weise zum Ersatze der zerstörten Hauptzellen dienen.

Bei zahlreichen Untersuchungen des Mageninhalts theils von saugenden, theils von erwachsenen Thieren, ist es mir niemals gelungen, den Austritt von freien, unveränderten adelomorphen Zellen auf die freie Magenoberfläche zu sehen, dagegen habe ich (die Thiere wurden zu diesem Zwecke aussschliesslich mit Stärkemehl gefüttert, um die Untersuchung nicht zu erschweren) im Speisebrei nnd im oberen Theil der Drüsen häufig in grosser Anzahl freie Kerne angetroffen, welche den Kernen der Hauptzellen sehr 
ähnlich waren. Ausserdem kann man bei sehr sorgfältiger Beobachtung in den unteren Theilen der Drüsen und im Lumen selbst eben solche Kerne auffinden, welche entweder vollkommen nackt sind ader von einer äusserst geringfügigen Zone von stark geschrumpftem und getribtem Protoplasma umgeben sind. Daher kann man nicht zweifeln, dass ein Untergang von Hauptzellen stattfindet, dass dieselben aber dabei nicht nach aussen gefuihrt werden, sondern in den Drüsen selbst durch irgend welehe degenerative Processe untergehen und dass ihr mebr widerstandsfähiger Theil - der Kern - davon unberührt bleibt. Zu Gunsten dieser letzteren Ansicht sprechen anch die mikroskopischen Bilder, welche an den Drtusen von Hunden erbalten werden bei Futterung derselben mit Phosphor uud Alkohol. Auf diese Weise gelingt es, wie ich schon friiher bemerkte, die funktionelle Thätigkeit der Drisen bis zum Maximum zu steigern, so dass der Process der Vermehrung der Belegzellen und der Untergang von Hauptzellen in weiten Grenzen beobachtet werden kann.

Beim Studium der Elemente in den Drïsen der Magenschleimhaut niederer Thiere, bei Fischen, wie auch bei einigen Amphibien und Reptilien, konnte ich bei denselben nur die Anwesenheit einer Art von Zellen in den Dräsenröhrchen konstatiren (hierher gehören die Fische: Esox lucius, Perca fluviatilis, von Amphibien und Reptilien: Rana, Triton, Tropidonotus natrix, Lacerta viridis, Emys europaca). Nach ihren chemischen Eigenschaften und nach ihrer Form sind die vollständig identisch mit den Belegzellen der höheren Thiere. Sie erscheinen entweder stark eckig oder von mehr runder Form mit zartkörnigem Protoplasma, mit grossem bläschenförmigem Kern, der nicht selten ein bis zwei Kernkörperchen enthält. Auch hier babe ich ziemlich oft Zellen mit zwei Kernen beobachten können.

Auf Taf. XI, Fig. 8, 9, 13, 14, 15 sind sowohl Zellen, als auch Drüsen von verschiedenen niederen Thieren dargestellt.

Obgleich unserer Auffassung nach die Hauptzellen als höher differenzirte Belegzellen anzusehen wären, wäre man dennoch nicht gentigend berechtigt, ibnen eine verschiedene Funktion abzusprechen, somit aber könnten wir auch nicht die allgemein bekannte Hypothese Heidenhain's über die Funktion der Belegund Hauptzelle ohne Weiteres bei Seite lassen.

Um sich daron zu tiberzeugen, ob die Belegzellen wirklich 
als Säurebildner betrachtet werden könnten, haben wir Versuche mit Tropäolin ${ }^{1}$ ) und Lakmus angestellt.

Tropäolin hat sich als ein zuverlässiges mikrochemisches Reagens erwiesen, da es nach meinen Versuchen geringste Mengen von freier Mineralsäure entdecken lässt $(0,01 \%)$. Indem ich die isolirten Drüsen eines gut durehgewaschenen Hundemagens mit einer Tropäolinlösung unter das Mikroskop brachte, nahmen wie die Hauptzellen, so besonders auch die Belegzellen nur eine gelbe Färbung, die einer neutral reagirenden Tropäolinlösung eigen ist, an. Daraus könnten wir schliessen, dass frische (lebendige) Beleg- und Hauptzellen keine freie Säure enthalten. Zu eben solchen, in diesem Sinne negativen Resultaten gelangte ich auch mit der mikrochemischen Reaction von Lakmus.

Da die Belegzellen bei einigen Präparationsmethoden in ganz frischem Zustande sich leicht isoliren lassen, unternahm ich nach dem Vorschlage des Herrn Prof. C. Z. Kutschin auch einige Versuche von kinstlicher Verdaung mit solchen isolirten Zellen, welche in schwacher ClH-Lösung (1 pro Mille) vertheilt w urden.

Stiickchen von ganz frischem und gut ausgewaschenem Fibrin, zu feinsten Fäserchen zerzupft, wurden in das Präparat mit den Belegzellen hineingethan. Diese sammt der Säure befanden sich in der napfförmigen Vertiefung des hohl ausgeschliffenen Objektträgers. Nachdem ich einige mehr oder weniger geeignete Stellen im Präparate durch mikroskopische Untersuchung bestimmte, wurde der Objectträger mit einem Deckgläschen bedeckt und der Einwirkung der Temperatur von $38^{\circ}$ ausgesetzt. An einem Präparate, welches nach einer halben Stunde herausgenommen und der mikroskopischen Betrachtung unterzogen wurde, zeigte sich, dass an den Fibrinfasern schon eine ziemlich bedentende Lösung eingetreten war, vornehmlich an den Fasern, welche den Belegzellen am nächsten gelegen waren. An den Belegzellen selbst bemerkte man ausser einer gewissen Aufhellung und Aufquellung noch keine besonderen Veränderungen.

Nach Verlauf einer weiteren halben Stunde ungefähr, konnte

1) Von v. d. Velden zuerst als makroskopisches Reagens angeführt, s. "Ueber das Fehlen der freien Salzsäure im Magensaft". Deutsches Archiv $f$. klinisahe Medicin. XXVII, p. 186. 
man am Präparate eine fast vollständige Lösung des Fibrins konstatiren. Die Belegzellen waren jetzt bis zur Unkenntlichkeit verändert. An ihrer Stelle (zwar nicht bei allen, jedoch den meisten derselben) fand ich Gebilde, welche wie einen feinkörnigen Zerfall derselben darstellten, mit einem mattglänzenden centralen Theile, welcher dem Kerne der Belegzellen entsprach; letzterer hatte jedoch, wenn auch dem Ansehen nach durch Aufquellung etwas verändert, dennoch seine früheren Umrisse behalten. Die äusseren Contouren der Belegzellen traten nur sehr undeutlich hervor und erschienen wie verwachsen.

Bei noch längerem Digeriren zeigte das Präparat keine weiteren deutlichen Veränderungen im mikroskopischen Ansehen, so dass ich mich mit dem bisherigen begnügte und bei den Resnltaten, die ich durch eine künstliche Verdaung von einer Stunde und zwanzig Minuten erbalten hatte, stehen blieb.

Mit diesen Versuchen zugleich stellte ich in genau derselben Weise andere an, bei welchen das Blutfibrin durch das schwerer verdauliche geronnene Hühnerweiss ersetzt wurde; vom letzteren wurden feinste Schnitte entnommen und in Säure mit Belegzellen hineingebracht, alsdann der Einwirkung von Temp. $38^{\circ}$ ausgesetzt.

Parallel hiermit wurden Controlversuche mit kïnstlicher Verdauung angestellt, indem Fibrin und geronnenes Eiweiss in Berührung mit Säure allein gebracht wurden.

Schliesslich schien es mir am sichersten und bequemsten, aut dieselbe Art - und Weise mehr oder weniger genau auch die verdauende Fähigkeit der Formelemente der Drüsen von niederen Thieren, von Frosch und von Fischen zu bestimmen. Hier liegt die Sache einfacher auch in der Beziehung, dass wie früher erwähnt, bei diesen Thieren die Drüsen nur eine Art zelliger Elemente enthalten, so dass es nicht nöthig ist, die Versuche mit den besonderen Vorsichtsmaassregeln anzustellen, wie bei den böheren Thieren.

In der folgenden Tabelle sind die Resultate der Versuche ubersichtlich zusammengestellt.

Wenn man in dieser Tabelle die Zeit vergleicht, welche zur Lösung von Fibrin und Eiweiss verbraucht wird, mit Betheiligung der Belegzellen und ohne dieselben, so wird man sich leicht überzeugen, dass die Anwesenheit dieser Zellen 


\begin{tabular}{|c|c|c|c|c|}
\hline Thierart. & $\begin{array}{l}\text { Nr. } \\
\text { des } \\
\text { Ver- } \\
\text { suchs. }\end{array}$ & & $\begin{array}{c}\text { Temp. } \\
\text { nach } \\
\text { Cel- } \\
\text { sius. } \\
\end{array}$ & \\
\hline Katze. & I. & $\begin{array}{l}\text { Fibrin + Belegzellen } \\
+ \text { ClH (1 pro 1000). }\end{array}$ & $37,5^{0}$ & $\begin{array}{c}\text { Anfang der Lösung ungefähr } \\
\text { nach } 1 / 2 \text { Stunde, nach } 3 / 4 \text { Stunden } \\
\text { fast vollständige, nach } 1 \text { Stunde } \\
10 \text { Minuten vollständige } \\
\text { Lösung. }\end{array}$ \\
\hline dito. & II. & $\begin{array}{l}\text { Fibrin + Belegzellen } \\
+\mathrm{CIH} \text { (1 pro 1000). }\end{array}$ & $38^{\circ}$ & $\begin{array}{c}\text { Nach ungefähr } 3 / 4 \text { Stunden } \\
\text { vollständige Lössung. }\end{array}$ \\
\hline dito. & III. & $\begin{array}{c}\text { Hühnereiweiss + Beleg- } \\
\text { zellen + ClH (1 pro 1000). }\end{array}$ & $38^{\circ}$ & $\begin{array}{l}\text { Anfang der Lösung bei } \\
\text { I Stunde } 20 \text { Minuten, fast voll- } \\
\text { ständig nach } 1 \text { Stunde } 40 \text { Minut. }\end{array}$ \\
\hline 1 & IV. & Fibrin + $\mathrm{ClH}$ & $38^{\circ}$ & $\begin{array}{l}\mathrm{Zu} \text { Ende der dritten Stunde } \\
\text { Anfang der Lösung. }\end{array}$ \\
\hline 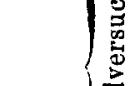 & V. & Fibrin + CIH. & $60^{\circ}$ & $\begin{array}{l}\text { Nach } 2 \text { Stunden } 15 \text { Minuten } \\
\text { noch nicht vollständige Lösung. }\end{array}$ \\
\hline $\mid \begin{array}{c}0 \\
0 \\
0\end{array}$ & VI. & Eiweiss + ClH. & $38^{\circ}$ & $\begin{array}{l}\text { Nach } 4 \text { Stunden } 20 \text { Minuten } \\
\text { fast ohne Veränderung. }\end{array}$ \\
\hline & VII. & Eiweiss + ClH. & $60^{0}$ & $\begin{array}{c}\text { Nach } 3 \text { Stunden sehr unbe- } \\
\text { deutende Lösung an den Rändern } \\
\text { und Aufquellung. }\end{array}$ \\
\hline Frosch. & VIII. & Fibrin + Zellen + ClH. & $20^{\circ}$ & $\begin{array}{l}\text { Anfang der Lösung annähernd } \\
\text { na.ch } 1 / 2-3 / 4 \text { Stunden. }\end{array}$ \\
\hline Hecht. & $I X$. & $\begin{array}{l}\text { Fibrin + Zellen + CIH. } \\
\text { Eiweiss + Zellen + ClH. }\end{array}$ & 320 & $\begin{array}{l}\text { Etwas füher als nach } \\
20 \text { Minuten war an den } \\
\text { Präparaten stellenweise } \\
\text { Lösung zu bemerken. }\end{array}$ \\
\hline
\end{tabular}

die Lösung oder Verdaung bedeutend beschleunigt und zwar vollziebt sich diese alsdannzwei bis drei Mal so schnell.

Bei kaltblïtigen Thieren tritt die energischste Lösung bei einer etwas niedrigeren Temperatur als bei warmblitigen ein; eine Erböhung der Temperatur beschleunigte nicht wie ich erwartet hatte, den Digestionsprocess, sondern verlangsamte im Gegentheil denselben. Ich habe daher in der Tabelle gerade die Temperaturen ausgewählt, bei welchen, wie es mir schien, die Verdaunng am besten vor sich ging und bei welchen die Lösung energischer eintrat. 
Gestiutzt auf die oben angeführten Facta scheint es mir, dass es nicht möglich ist einen Antheil der Belegzellen an der Pepsinbildung (gänzlich) zu leugnen. $E_{s}$ ist augenscheinlich, dass die Belegzellen ebenfalls eine Fermentsubstanz enthalten, welche, bei Gegenwart von freier Säure, mebr oder weniger energisch Fibrin and Eiweiss verdaut. $O b$ sich das Ferment, welches von den Belegzellen geliefert wird, von dem Ferment, welches durch die Hauptzellen secernirt wird, unterscheidet, kann ich natïrlich nicht entscheiden.

Es ist jedoch eben so augenscheinlich, dass das Ferment, welches von den drisigen Elementen bei niederen Thieren abgesondert wird, sich nach seinen chemischen Eigenschaften durchaus von dem Ferment unterscheidet, welches in den Belegzellen der höheren Thieren enthalten ist.

Indem ich jetzt zur Beschreibung des Druisenhalses ibergehe, muss ich bemerken, dass weder obere, noch untere Grenze desselben deutlich genug sind. Jedenfalls ist die obere mehr ausgeprägt. Bei der Mehrzahl der Säugethiere fällt der Drüsenhals durch seine dunklere Färbung auf. An Querschnitten, die durch das Niveau des Halses gehen, kann man sich leicht davon überzeugen, dass dieser Drïsentheil beiderlei Arten von Zellen enthält, wobei jedoch die Belegzellen hier uberwiegen.

Die letzteren haben hier gewöhnlich eine ovale Form, öfters jedoch auch eine conische und erreichen mit ihrem verjüngten Ende bisweilen das Lumen selbst. Ungefähr im unteren Drittel des Halses versehwinden die Hauptzellen vollständig, so dass der obere Theil des Halslamens ausschliesslich mit Cylinderepithelzellen ausgekleidet ist. Vergleicht man diese Zellen mit denen, welche bei Embryonen T'richter und Hals auskleiden, so wird man zu dem Schlusse kommen, dass dieselben keine besondere Formen darstellen, sondern dass sie einfach als Cylind erepithelzellen zu betrachten seien, welche bei den erwachsenen Thieren den Embryonalcharakter beibehalten, da sie nach Färbung und Form vollständig an Embryonalepithelzellen erinnern. Ihr Hauptunterschied vom Epithel der Oberfäche besteht im Mangel einer schleimigen Metamorphose. Hierbei ist zu bemerken, dass das Epithel der Oberfläche beim Embryo ebenfalls auch am freien Ende keine Spur von schleimiger Metamorphose zeigt. Die Belegzellen erstrecken sich weit höher hinauf and man kann sie zwischen und unter den 
Cylinderepithelzellen antreffen, selbst nahe an den Drïsenöffnungen.

Ich kann nicht der Meinung Stöhr's beipflichten, welcher behauptet, dass alle Belegzellen des Trichters unbedingt zwischen den Cylinderepithelzellen liegen und mit ihren verjüngten Enden bis zum Lumen vordringen (s. Taf. XI, Fig. 6).

Die Pylorusdrüsen unterscheiden sich, wie sehon seit den Angaben Heidenhain's und den Arbeiten E bstein's bekannt ist, ziemlich scharf von den Drüsen des Fundus und der Cardia, sowohl nach ihrer äusseren Form als auch durch die Elemente, welche die Drissenröbrehen auskleiden und den Hauptzellen entsprechen. Bei den Pylorusdrüsen erscheinen die Trichter sehr breit und lang und sind mit Cylinderepithelzellen besetzt, welche schleimige Metamorphose zeigen. Der Hals, der hier nur einen verhältnissmässig geringen Theil des ganzen Röhrchens ausmacht, ist nur mit kurzcylindrischen Zellen ausgelegt, die sich in Folge ihres Körnerreichthums intensiver färben, als das Epithel der Oberfläche. Diese Zellen sind mit den Elementen im Halse der Cardia- und Fundusdrüsen identisch. Der eigentlich drüsige Theil des Röhrchens ist mit hellen Zellen ausgekleidet, von etwas conischer oder cylindrischer Form, welche nach Färbung und mikrochemischen Reactionen den Hauptzellen in den Pepsindrüsen gleic ben.

Ausser den Zellen, welche ich als mit den Hauptzellen identisch betrachte, gelang es mir einige Male in den Pylorusdrüsen zwischen den hellen, cylindrischen Zellen besondere Gebilde zu beobachten, welche den Belegzellen sehr ähnlich sind. Diese Zellen finden sich in sehr geringer Anzahl vor und treffen sich nicht an allen Querschnitten der Drüsenröhrchen an. Ihre Form ist eine keilförmig verlängerte, sie erscheinen etwas schmaler als die Belegzellen (s. Taf. XI, Fig. 12a) und dringen mit ihrem Ende fast immer bis zum Lumen vor. Mit diesen Zellen zugleich trifft man auch andere Formen von Zellen von grossem Umfange und nicht von keilförmiger, sondern mehr dreieckiger, bisweilen deutlich ovaler Form an, welche gleichsam Uebergangsformen zu echten Belegzellen bilden. Sie färben sich intensiv schwarz durch 0 smiumsäure und bei Färbung durch Anilinfarben (Anilinblau in wässeriger Lösung) durch Eosin und Carmin heben sie sich durch ihre dunkle 
Farbe von den tibrigen, benachbarten; hellen, nicht sich färbenden Hauptzellen deutlich ab $^{1}$ ).

An isolirten Drüsen erscheint die Membrana propria der Magendrüsen überhaupt im optischen Längsschnitte als homogener glasartig glänzender, sehr dünner, aber doch deutlich doppeltcontonrirte Streifen, welcher sich in der ganzen Ausdehnung der Drüse vom Trichter bis zum blinden Grunde erstreckt. Die Membran ist so innig mit dem Inhalte der Driisen verbunden, dass es im frischen Zustande unmöglich zu sein pflegt, ihre Structur zu studiren und dass man fast immer seine Zuflucht entweder zur mechanischen Zerstörung der Drüsenröhrchen oder zum Ausspülen mittelst des Pinsels oder auch zur Wirkung gewisser chemischer Reagentien nehmen muss. Unter Einwirkung schwacher Alkalilösungen auf frische Drüsenschläuche wird nach Zerstörung der in denselben enthaltenen Drüsenelemente die Membran völlig conservirt in ihrer ganzen Ausdehnung erhalten. Bei nachfolgender Färbung mit Hämatoxylin hat sie das Aussehen eines zarten, hyalinartigen, mit zerstreuten Kernen durchsetzten Cylinders. An Präparaten, welche einige Zeit in Müller'scher Flüssigkeit lagen oder in Chloralhydratlösung macerirt wurden, trifft man nach sorgfältigem Zerzupfen Bruchstïcke der Membrana propria an und zwar in solcher Weise, dass sie sich von der Oberfläche darstellen. Dabei gelingt es an derselben sternförmige Gebilde mit ovalem, rundlichem, ziemlich grossem Kern zu beobachten. Bei Hämatoxylintinction treten die Kerne noch deutlicher hervor, während die Contouren der einzelnen Zellen nicht deutlicher werden.

Unmittelbar unter der Oberfläche der Schleimhaut zeigt sich die Membrana propria schon nicht mehr als eine homogene gleichmässige Membrana, sondern erscheint dieselbe gleichsam durchlöchert und in den Zwischenräumen zwischen zwei Trichtern geht sie über oder bildet vielmehr jene subepitheliale Schicht, die schon früher von mir beschrieben worden ist.

1) Ich muss hier erwähnen, dass bei der Untersuchung der Pylorusdrüsen das Lumen derselben niemals von Kernen oder anderen, auf Zellenreste deutenden Gebilden ausgefüllt angetroffen wird. $\mathrm{Zu}$ demselben Resultate gelangte in seinen Untersuchungen auch Prof. C. Z. Kutschin, der meine Aufmerksamkeit besonders auf diesen Umstand lenkte. Wäre nicht auf diese Art die geringe Anzahl der anzutreffenden Belegzellen zu erklären? 
In Bezug auf ihre Dicke erleidet die Membrana propria wenig Veränderungen und zeigt sich bei fast allen Thieren ohne Ausnahme von derselben Mächtigkeit. Man muss jedoch hinzufügen, dass sie in den Drüsen von Embryonen bedeutend dicker erscheint, ein weniger festes Gefüge zeigt und sich nicht an allen Stellen gleichartig erweist und bisweilen sogar den Eindruck hervorbringt, als ob sie geschichtet sei.

Die bindegewebige Grundlage der Magenschleimhaut zeigt je nach den verschiedenen Stellen und auch je nach den Thierspecies bedeutendere Schwankungen, als die früber beschriebenen Theile der Schleimhaut, sowohl in Bezug auf ihre Festigkeit, als auch auf den ungleichen Gehalt an verschiedenen Formelementen. Man kann sie in zwei Abtheilungen trennen: eine, die die Gruppen von Drüsen oder einzelne derselben umgiebt, das wäre der interglanduläre Theil des bindegewebigen Gerüstes der Mucosa, und in einen subglandulären, der unter dem blinden Grunde der Driisen gelegen ist und in enger Verbindung einerseits mit der Zwischendrüsenschicht, anderseits mit dem submucösen Bindegewebe steht.

Bei den höheren Thieren (Katze, Hund) trägt der interglanduläre Theil einen Uebergangscharakter von gewöhnlichem fibrillären Bindegewebe zur areolären Form desselben. Seine Bestandtheile sind: Einzelne mehr oder weniger sclerosirte Bindegewebsfasern entweder einzeln verlaufend oder zu zarten, lockeren Bündeln vereinigt und sternförmige Bindegewebszellen. Die letzteren zeigen zwei bis drei Fortsätze, in deren Maschen alsdann in grösserer oder geringerer Zahl lymphoide Elemente von verschiedener Grösse eingelagert sind. Viele von denselben enthalten je zwei Kerne oder weisen dentliche Anzeichen von Theilung auf.

Glatte Muskelfasern treten am Grunde der Drüsen in die Zwischenräume zwischen denselben ein in Gestalt von ziemlich dicken Bündeln. Diese theilen sich aber bald in kurze, dünnere Bündelchen, welche man an ihrer mehr oder weniger intensiven Färbung mittelst Hämatoxylin erkennen kann, an ungefärbten Präparaten noch leichter an ihren stäbchenförmigen Kernen.

Solche zarte Muskelzïge laufen mehr oder weniger vertical, folgen dabei gewöhnlich einem Blutgefässstämmchen, indem sie dasselbe an einer Seite begleiten oder es überkreuzen und sich allmählich der Wand des Drüsenröhrchens nähern. Sie erstrecken 
sich bis zu einer ziemlich bedeutenden Höhe, fast bis zur Epithelschicht, wo sie besonders scluwer zu erkennen sind. In ihrem Verlauf anastomosiren diese feinen Muskelzüge sowohl miteinander, oder auch mit grösseren die Blutgefässstämmchen begleitenden Biindeln. Hierbei ist zu bemerken, dass das Bindegewebe zwischen den Drüsen nicht gleichmässig vertheilt ist, sondern so, dass dieselben durch bedeutendere Septa in einzelne grössere oder kleinere Gruppen getheilt erscheinen. In diesen Septen liegen venöse Stämmchen, die die Dicke der Schleimhaut ersetzen, um in die Submucosa zu gelangen.

An Querschnitten, welche ausgepinselt und mit Hämatoxylin oder Eosin gefärbt sind, ist diese Vertheilung des Bindegewebegeristes am bequemsten zu studiren. Sowohl an Dicken- als Flächenschnitten der Magenschleimhaut kann man sich leicht daron tiberzeugen, dass die Mächtigkeit der Muskelbündel zu der Mächtigkeit der sie enthaltenden Bindegewebssepten parallel sich verhält.

Am stärksten ist das interstitielle Gewebe in der Gegend des Halses der Drüsen entwickelt.

Bei einigen niederen Wirbelthieren (z. B. Fisch, Frosch, Tropidonotus natrix) ist das bindegewebige Stroma in der ganzen Ausdehnung der Magenschleimhaut sehr stark entwickelt, wodurch das Isoliren der einzelnen Drïsen schwerfällt. Solche Entwickelung erreicht bei höheren Thieren das bindegewebige Stroma nur in der Pylorusgegend.

Aus dem Bindegewebe der Submucosa dringen öfters einzelne Fasern und Faserbündelchen in die lamellöse Schicht des Bindegewebegerilstes, wodurch sie demselben eine grössere Dichte und Festigkeit verleihen.

In der Schleimhaut des Magens von Kaninchen und Katze zwischen Muscularis muscosae und der subglandulären Schicht finden wir eine lamellenartige Lage, welche, soviel mir bekannt, zuerst von Zeissli) bei der Katze und erst kürzlich in der bindegewebigen Grundlage des Dunndarms bei Hunden von N. K. Kult-

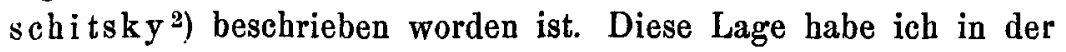

1) Zeiss l, M.: „Ueber eine eigenthümliche Schichte im Magen der Katze." Wien. Sitzb. Bd. LXXII. Heft I u. II. 1875. p. 8.

2) Kulschitsky, N.: ,Zur Frage über den Bau der Dünndarmschleimhaut und den Mechanismus der Aufsaugung. Charkow. 1882. p. 4 (russisch). 
ganzen Ausdehnung von der Cardia bis zum Pylorus angetroffen. Sie hat ein homogenes, mattglänzendes Aussehen und an einigen Stellen einen stark gewellten Verlauf. Ihre Dicke bleibt sich fast in der ganzen Ausdehnung gleich, schwankt jedenfalls sehr wenig. Bei Färbung von Präparaten aus Alkohol mit verschiedenen Färbstoffen (Carmin, Anilin, Hämatoxylin) bleibt die Substanz dieser Lage fast farblos oder färbt sich sehr schwach. Intensive Färbung mit Hämatoxylin macht in derselben einige Formelemente sichtbar, welche sich wie sclerosirte Bindegewebskerne ausnehmen. Ausser diesen Gebilden glückt es an Präparaten aus Alkohol keine anderen geformten Bestandtheile in dieser Lage mehr zu bestimmen.

Nach unten hin ist diese Lage scharf von der circulären Muskelschicht geschieden, nach oben hin zeigt sich die Grenze nicht so scharf ausgeprägt, da dieselbe sich hier eng dem an Kernen reichen bindegewebigen Stroma anschliesst. Bisweilen wird diese Lage in der Richtung von oben nach unten durchsetzt von vereinzelten Bindegewebsfasern, besonders interessant erscheinen solche Präparate in welchen Blutgefässe in Begleitung von Bündeln glatter Muskelfasern diese Lage durchsetzen (s. Taf. XI, Fig. 12).

Es ist mir auch bei einigen Fischen (Esox) diese Lage zu beobachten gelungen und konnte ich hierbei dieselbe von ihrem Ursprunge an verfolgen, was mir einige Aufklärung in Betreff ihrer Structur gab. Im Oesophagus nämlich nicht weit von der Stelle, wo die Schleimhaut desselben in die des Magens übergeht, kann man bemerken, wie der tiefer gelegene Theil der bindegewebigen Grundlage allmählich sich verdickt, wie die einzelnen Bündel desselben dicker werden und zuletzt eine dicke Lage, aus 5-7 starken Bindegewebsbündeln zusammengesetzt, bilden. Diese Bündel sind stark sclerosirt und dem Ansehen nach völlig homogen; sie sind in Bezug auf ihre äusseren Contouren, nach ihrem Verhalten zu Färbstoffen und endlich ihrer Lage nach der Zeissl'schen lamellenartigen Schicht in der bindegewebigen Grundlage der Magenschleimhaut der Katze sehr ähnlich. Mir scheint es, dass eben diese Zeissl'sche Schicht, in Analogie mit dieser Bildung bei Fischen, betrachtet werden muss als einfache Verdickung der tiefer gelegenen Abtheilung der bindegewebigen Grundlage, welche stark sclerosirt ist und sich in Form einer solchen homogenen lamellenartigen Schicht darstellt.

Ich muss hier noch, wenn auch in Kürze, der letzten Schicht, welche in die Zusammensetzung der Magenschleimbaut im engeren Sinne des Wortes, eingeht, gedenken, nämlich ihrer Muscularis mucosae. Sie erscheint als die Fortsetzung einer Muskelschicht, welche in der Oesophagusschleimbaut ihren Anfang nimmt und 
liegt als Grenzschichte zwischen der bindegewebigen Schicht der eigentlichen Schleimbaut und deren Submucosa. Diese Schicht besteht aus zwei scharf ausgeprägten Lagen von glatten Muskelfasern, einer innern ringförmigen und einer äus seren der Länge nach verlaufenden, doch erhält sich diese Anordnung weitaus nicht in allen Theilen der Magenschleimhaut. Von der Cardia angefangen bis zum Pylorus kreuzen sich sowohl die Fasern der inneren, als der äusseren Lage in verschiedenen Richtungen mit einander, so dass einzelne Bündel der inneren Lage nach aussen gehen und die Richtung der Fasern annehmen, welche der äusseren Lage angehören und umgekehrt erheben sich Bündel aus der äusseren Lage zur inneren; letztere Bündel verlaufen eine Strecke lang in schräger Richtung, gehen aber später vollständig in die Richtung der Bündel der inneren, ringförmigen Lage über. Beide Lagen sind ron einander dureh eine äusserst dünne, bisweilen kaum bemerkbare Zwischenschicht von fibrillärem, stellenweise recht lockeren Bindegewebe getrennt. Im Cardiatheil erscheint die Längslage gewöhnlich etwas dicker als die ringförmige.

Ausser diesen zwei eben erwähnten Lagen, der ringförmigen und der der Länge nach verlaufenden, folgen auf diese letztere noch glatte Muskelfasern, welche ausserdem nicht in gleichen Abständen von einander liegen, von einander durch Zwischenbündel vom lockeren Bindegewebe abgegrenzt werden, welche eigentlich schon der Subumcosa angehören. Die Bündel dieser sozusagen dritten Lage verlaufen gewöhnlich fast schräg, oder mehr oder weniger circulär (s. Taf. XI, Fig. $12 \mathrm{f}, \mathrm{s}$ ).

Was diejenigen Muskelbündel anbetrifft, welche zwischen den Drüsenröhrchen aufsteigen, so ist über deren Verhalten schon früher verhandelt worden. In Bezug auf ihren Ursprung kann man beifïgeu, dass sie bald aus der inneren ringförmigen, bald, und sogar häufiger, aus der längsverlaufenden Lage aufsteigen (s. Taf. XI, Fig. 12e).

Als Resultat meiner Untersuchungen glaube ich die nachfolgenden Sätze aufstellen zu können:

1) Das Epithel, welehes die Oberfläche der Magenschleimhaut bekleidet, trägt bei allen Wirbelthieren 
den Charakter von Cylinderepithel, wobei in der Magenschleimhaut einiger namentlich niederer Thiere (Bars, Hecht, Frosch) a uch Flimmerepithel angetroffen wird, dessen Zellen aber als Residuum der Embryonalperiode zu betrachten sind.

Die Epithelzellen auf den Zotten der Dünndarmschleimhat nehmen ihren Ursprung aus Flimmerepithelzellen.

2) Eine subepitheliale Schicht in dem Sinne, wie sie Debove annimmt, existirt nicht. Unmittelbar unter dem Epithelium der Magenoberfläche jedoch findet sich eine Art von gefensterter Membran vor, welche aus sclerosirten Endothelialplättchen besteht, die mit der Membrana propria der Drüsen, sowie mit den feinen Bindegewebsfasern des eigentlichen Stroma der Magenschleimhaut in Verbindung stehen.

3) Im Drüsenhalse finden sich Zellen von dreifacher Art vor: im oberen Theile wird ein leicht abgeplattetes Cylinderepithel ohne Schleimmetamorphose angetroffen, dessen Zellen nach Färbung und Form mit den Zellen der Embryonalperiode identisch sind; im unteren Theile ist das Lumen von Haupt- und Belegzellen begrenzt, wobei letztere an Zahl vorwiegen.

4) Die Beleg- und Hauptzellen der höheren Wirbelthiere sind nicht verschiedene Gebilde, sondern stellen nur verschiedene $S t u$ fen in der Differenzirung von Zellenelementen dar, wobei die Belegzellen einen deutlicher ausgesprochenen protoplasmatischen Character a ufweisen und sich weniger differenzirt zeigen, als die Ha uptzellen, in welche sie übergehen nach vermehrtem Verbrauch oder Untergang der letzteren.

5) Während der Zeit der erhöhten Function (während der Verdauung, bei Fütterung mit Phosphor und Alcohol) geht eine bedeutende Vermehrung der Belegzellen vor sich.

6) Bei niederen Wirbeltbieren (Esox, Perca fluviatilis, verschiedene Arten von Rana, Emys europaea, Tropidonotus natrix) konnte nur das Vorhandensein einer Art von Zellen constatirt werden, die vollkommen den Belegzellen der höberen entsprechen. 
7) Aus Versuchen mit künstlicher Verdauung ergiebt sich, dass die Belegzellen der böheren Wirbelthiere, ebenso aber auch die Drüsenzellen niederer Wirbelthiere (Hecht, Frosch) Pepsin bereiten, da bei ihrer Anwesenheit eine energische Verdaung von Fibrin und Eiweiss ron Statten geht.

8) Mittelst Tropaeolin und Lakmus angestellte mikrochemische Reactionen sprechen gegen die Auffassung der Belegzellen als Säurebildner.

9) Die Zellen der Pylorusdrusen sind identisch mit den Hauptzellen in den Fundus-und Cardiadrusen.

Indem ich diese Arbeit der Oeffentlichkeit ïbergebe, halte ich mich verpflichtet, meinem hochverehrten Lehrer Herrn Professor C. Z. Kutsehin, in dessen Laboratorium ich meine Untersuchung. anstellte and der mir allezeit mit Rath und That in freundlichster Weise entgegen kam, meinen Dank auszusprechen.

\section{Tafelerklärung.}

Tafel $\mathbf{x}$.

Fig. 1. Cylinderepithelzellen mit schleimiger Metamorphose vom Epithel der Magenoberfläche und der Trichter aus der Magenschleimhaut der Katze - a, b, c, d, e; Epithelzellen von der Oberfläche an - f; Präparat aus Müll. Flüssigkeit. Zeiss. Syst. E, Ocular 4.

Fig. 2. Isolirte Epithelzellen von demselben Objekte, theils in indifferenten Flüssigkeiten untersucht, theils bei Zusatz von Wasser, a - aufgequollene, schleimig metamorphosirte Zellen; b, c, d, e - Zellen, welche zum Theil geschlossen, zum Theil offen sind, in denen die schleimige Metamorphose weniger deutlich ausgeprägt ist. Zeiss. System E, Ocular 4.

Fig. 3. Epithelium von der Magenschleimhaut des Frosches; a, b - Zellen mit deutlich ausgesprochener schleimiger Metamorphose; $d$ - Becher-

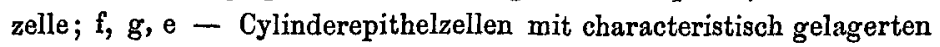
Kernen, ohne schleimige Metamorphose; c - junge, protoplasmatische, keulenförmige Cylinderzelle. Präp. aus Müll. Flüss. Zeiss. Syst. E, Ocul. 4. 
Fig. 4. Epithel der Magenoberfläche von Tropidonotus natrix. Präp. aus Mï 1l. Flüss. Zeiss. System E, Ocul. 2.

Fig. 5. Isolirte Epithelzellen aus d. Magenschleimhaut von Esox lucius. Präp. aus Müll. Flüss. Hartnack. Syst. 9, Ocular 3.

Fig. 6. Flimmerepithelzellen von d. Magenschleimhaut des Frosches. Jodserum. Hartnack. Syst. 9, Ocul. 3.

Fig. 7. Keulenförmige Cylinderzellen von d. Magenschleimhaut des Frosches. Müll. Flüss. Zeiss. Syst. E, Ocular 4.

Fig. 8. Becherzellen aus dem Oesophagus des Frosches. Zeiss. Syst. 4, Ocul. 2.

Fig. 9. Verschiedene Uebergangsformen von Becherzellen zu Schleimzellen von demsèlben Thiere. Müll. Flüss. Z e iss. Syst. E, Ocul. 4 .

Fig. 10. Verschiedene Zellenformen von der Epitheldecke der Oesophagusschleimhaut von Cobitis fossilis. Müll. Flüss. Zeiss. Syst. E, Ocular 2.

Fig. 11. Isolirte Epithel- und Becherzellen von der Magenschleimhaut des Igels; a, b, c - Epithelzellen; d, e, f - Becherzellen; g - zwei Epithelzellen mit einer zwischen den Fusstheilen derselben eingeschlossenen Ersatzzelle. Müll. Flüss. Zeiss. Syst. E, Ocular 2.

Fig. 12. Epithel der Magenschleimhaut von Emys europaea; a, c, Epithelzellen geschlossen und ohne schleimige Metamorphose; b, e, d schleimmetamorphosirte Epithelzellen. Müll. Flüss. Zeis s. Syst.E, Ocul. 2.

Fig. 13. Von demselben Thiere: a - einzelne Ersatzzellen; b - ein Aggregat derselben; c - Cylinderzelle mit langem Hals und rüsselförmig endender Spitze. Präparat aus Müll. Flüss. Zeiss. Syst. E, Ocul. 4.

Fig. 14. Becherzellen von verschiedener Form aus dem Oesophagus von Tropidonotus natrix: $a$ - Becherzelle mit Flimmerhä̈̈rchen; $b-\mathrm{Be}-$ cherzelle mit deutlich ausgeprägtem protoplasmatischem lnhalt; $c$, d - Becherzellen mit stark schleimiger Metamorphose. Humor aquaeus. Syst. Zeiss. C. 4.

Fig. 15. Ebstein's Ersatzzellen: a - von der Magenschleimhaut des Hechtes; b - von der Katze. Müll. Flüss. Zeiss. E. 4.

Fig. 16 u. 17. Zellen von endothelialem Charakter aus der subepithelialen Lage Debove's. Friseh untersucht. Hartnack. Syst. 9. Ocular. 3.

Fig. 18. 1)rüsen des Hundes, frisch a: von einem hungernden Thiere: $b$ von einem gefütterten. Zeiss. Syst. E, Ocular 2.

\section{Taf. XI.}

Fig. 1, a - am meisten typische Formen von Belegzellen bei Säugethieren (Katze, Hund) ; b, c, d, e, f, g, h, m - verschiedene Phasen von Theilung der Belegzellen; n, l - junge Belegzellen. Präparate theils frisch, theils aus Müll. Flüssigkeit. Hartnack. Syst. 9. Ocul. 3. 
Fig. 2. Belegzellen aus d. Magenschleimhaut der Maus. Jodserum. Zeiss. Syst. E. Ocul. 2.

Fig. 3. Belegzellen aus d. Magenschleimhaut der Ratte. Jodserum. Zeiss. Syst. E. Ocul. 2.

Fig. 4. Isolirte Drüsenzellen, welche Uebergangsformen von Beleg- zu Hauptzellen darstellen. Aus dem Magen der Ratte. Müll. Flüss. Zeis s. Syst. E. Ocul. 2.

Fig. 5. Durchschnitt der Magenschleimhaut des Hundes. Vom Fundus. Färbung mit Anilinblau nach Heidenhain's Methode. Präp. aus Mäll. Flüss. und Alkohol: $a-$ Trichter; b - Drüsenhals; $c-$ Drüsengrund; $f$ - Belegzellen; $g$ - Hauptzellen; i - schwach gefärbte Uebergangsstufen. Zeiss. Syst. E. Ocul. 2.

Fig. 6. Durchschnitt durch Trichter und Hals einer Drüse des Hundes. Präp. aus Alkohol. Färbung durch Carmin. Syst. Zeiss. E. 2.

Fig. 7. Durchschnitt durch den unteren Theil einer Drüse. Hund. Färbung mit Eosin und Hämatoxylin. a - Uebergangsformen; b - Belegzelle, die mit ihrem zugespitzten Ende das Lumen erreicht; c Belegzelle, wo der Kern nicht in den Schnitt gekommen ist. Zeiss. Syst. E. Ocul. 2.

Fig. 8. Isolirte Drüsenzellen aus d. Magenschleimhaut von Tropidonotus natrix. Frisch. Zeiss. E. 4.

Fig. 9. Solche aus d. Magenschleimhaut von Emys europaea, id.

Fig. 10. Querschnittt durch eine Drüsengruppe aus d. Magenschleimhaut eines gefütterten Hundes; $a-$ zweikernige Belegzelle; $b$ - Uebergangsformen; c - Belegzelle, die das Drüsenlumen erreicht. Präp. aus Müll. Flüssigkeit und Alkohol. Färbung mit Carmin nach $\mathrm{Hei-}$ denhains Methode. Hartnack Syst. 9. Ocular 3.

Fig. 11. Querschnitt durch ein Drüsenröhrchen der Magenschleimhaut der Maus; a - zwei doppelkernige Zellen. Behandlung, wie in der vorigen Figur. Hartnack. Syst. 9. Ocul. 3.

Fig. 12. Präparat vom Pylorustheil der Magenschleimbaut von der Katze. Müll. Flüssigkeit und Alkohol. Färbung mit Carmin. a - Belegzellen; b - Hauptzellen; $\mathrm{c}-\mathrm{Z}$ eiss I'sche homogene Schicht; I u. IIMuscularis mucosae: I - circuläre Schicht; II - longitudinal verlaufende Muskelfasern; einzelne vertikal verlaufende Muskelfasern; f - schräg verlaufende Muskelbindel. s, e - Zeiss. Syst. C. Ocul. 4. vgl. den Text.

Fig. 13. Querschnitt von Drüsen der Magenschleimhaut von Perca fluviatilis. Alkoholpräparat. Syst. Zeis 8. C. 2.

Fig. 14. Isolirtes Drüsenröhrchen aus der Magenschleimhaut von Esox lucius. Müll. Flüssigkeit. Zeiss. Syst. E. Ocul. 2.

Fig. 15. Präparat aus der Magenschleimhaut des Frosches. Müll. Flüssigkeit und Alkohol. Zeiss. Syst. E. Ocul 2. 